DOI 10.15826/B978-5-7996-3073-7.9

\author{
Marina V. Klimenskikh \\ Ayad Hajar \\ Kaur Harleen \\ Alsaykal Sura \\ Ural Federal University, \\ Ekaterinburg, Russia
}

\title{
The problem of identifying cognitive and emotional factors of academic success in an online course ${ }^{*}$
}

Abstract: We studied the psychological factors associated with the efficiency of online learning by using a sample of students from a Russian university (Ural Federal University). We used as a point of departure the idea of adaptive learning, which assumes that academic success in an online course is associated with the characteristics of cognitive, emotional, volitional and other areas of a student's personality. The resulting general linear model includes such factors as internal motivation, external motivation, intelligence, personal qualities, training experience and openness to experience, which have an extremely low proportion of explained variance $-3 \%$. Based on the above research, the key conclusion was made that a successful student is successful in any training format. In other words, the focus of search for improving the efficiency of online learning should be not only on the psychological characteristics of those students who are successful in the online format, but also on improving the pedagogical design of the online course.

Keywords: Mass online courses (MOOK), Internet-course, adaptive learning, individual educational trajectory, psychological characteristics of students

Introduction. The massive shift to remote forms of learning due to the coronavirus pandemic has put into the spotlight the quality and effectiveness of online educational programs. In comparison with faceto-face training, an online course has a number of peculiarities and it

* This study was funded by the Russian Foundation for Basic Research (grant № 17-36-01069). 
requires students to have special psychological competencies. In our study, we use as a point of departure the concept of adaptive learning [1]. The research literature describes several ways to adapt online courses in terms of organization and methodology by taking into account the psychological characteristics of students. To date, a number of studies have been conducted to identify the relationship between academic success and psychological characteristics of online course participants. However, the connection between students' psychological characteristics and their willingness to study online is still not quite clear. There is evidence that an important role in this process is played by the cognitive and emotional factors [2].

Materials and methods. Our research relies on the following methods: the Scale of Progressive Matrices of J. Raven, the Big Five questionnaire and its modification, the Scale of Academic Motivation of T. O. Gordeeva, E. N. Osina, O. A. Sycheva, The Scale of Self-Control of T. O. Gordeeva, the Test Questionnaire of Self-Organization of Activity (OSD) adapted by E. Yu Mandrikova, Diagnostics of the Volume and Accuracy of ShortTerm Verbal and Logical Memory in R. Amthauer's interpretations; diagnostics of the volume, switchability and distribution of attention of the "Schulte-Gorbov Table"; and diagnostics of the dominant perceptual modality (S. Efremtseva). At the pilot stage, a questionnaire survey was conducted to find out the views of students and faculty about the prospects for the development of online learning format. The following methods of mathematical statistics were used: correlation analysis (Pearson's method), comparative analysis (student's t-test), factor analysis by the principal component method, and a general linear model. The study, which covered a total of 860 respondents, was conducted over three years in several stages. At each stage we adjusted the hypotheses and methodology, depending on the results obtained.

Results. Based on the results of data processing, a general linear model was obtained, which included psychological predictors of successful learning in an online course. However, the proportion of explained variance is only $3 \%$. Despite this modest result, it is mathematically reliable and can be taken into account as indicating the main trends in the manifestation of the mental characteristics of successful and unsuccessful students of online courses. Therefore, exploratory factor analysis has shown that 
six factors can be determined (see the table below). The first factor (F1) can be called the internal motivation factor. The second factor (F2) can be defined as an intelligence factor, a classic predictor of learning. High positive loads for the third factor (F3) demonstrate components of external motivation associated with orientation towards public opinion, a sense of duty and guilt about a bad result. The fourth factor (F4) can be defined as personal qualities proper: the tendency to cooperate and agree with other people (benevolence), a strong-willed component of behavior (conscientiousness) as well as emotional sensitivity, anxiety and insecurity. The fifth factor (F5) was the factor of academic experience. Since most learning experience is obtained by respondents in the face-to-face format, those who have attended two or more online courses can be considered experienced. The participants in our sample received fairly high scores on online courses, so we can consider their experience a success. Finally, the sixth factor (F6) can be defined as a factor of openness to experience. All three sensory-perceptual modalities (auditory, visual, and kinesthetic) are included in one factor, which indicates that there is no priority for online learning among them. Openness to experience is a personal trait that integrates and directs all sensory-perceptual modalities. This remarkable psychological factor - "openness to experience" — revealed by the results of psycho-diagnostics of successful online students also confirms the feasibility of innovative technologies in higher education.

Table. Factor matrix of predictors of e-learning

\begin{tabular}{|c|c|c|c|c|c|c|}
\hline & 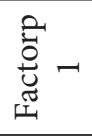 & 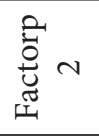 & 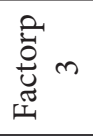 & $\begin{array}{l}0 \\
\stackrel{0}{0} \\
\stackrel{0}{\tilde{x}}\end{array}$ & 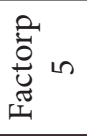 & مै \\
\hline Age & 0,03 & 0,00 & $-0,14$ & $-0,21$ & 0,79 & 0,13 \\
\hline Course & $-0,03$ & $-0,04$ & $-0,11$ & 0,29 & 0,71 & 0,15 \\
\hline Average Score & 0,29 & 0,16 & $-0,05$ & 0,08 & 0,19 & 0,29 \\
\hline Number of Items & 0,07 & $-0,01$ & 0,12 & 0,22 & 0,62 & 0,00 \\
\hline Extroversion & 0,08 & $-0,21$ & $-0,02$ & 0,42 & $-0,26$ & 0,42 \\
\hline Benevolence & 0,09 & $-0,01$ & 0,06 & 0,73 & 0,09 & 0,07 \\
\hline Good faith & $-0,06$ & $-0,01$ & 0,01 & 0,68 & 0,16 & 0,14 \\
\hline
\end{tabular}


End of table

\begin{tabular}{|c|c|c|c|c|c|c|}
\hline & 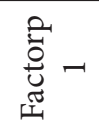 & 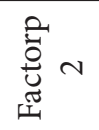 & 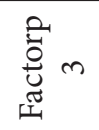 & 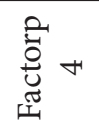 & 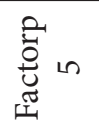 & 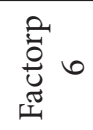 \\
\hline Neuroticism & $-0,12$ & 0,02 & 0,29 & $-0,54$ & $-0,07$ & 0,25 \\
\hline Openness to Experience & 0,04 & $-0,07$ & $-0,09$ & 0,39 & $-0,26$ & 0,57 \\
\hline Visual & 0,08 & 0,02 & $-0,05$ & 0,09 & 0,08 & 0,74 \\
\hline Audial & 0,05 & $-0,08$ & 0,11 & $-0,13$ & 0,14 & 0,67 \\
\hline Kinesthetic & 0,21 & $-0,04$ & 0,14 & $-0,10$ & 0,18 & 0,57 \\
\hline Cognitive Motivation & 0,83 & 0,10 & $-0,35$ & 0,02 & $-0,01$ & 0,02 \\
\hline Motivation Achievements & 0,85 & 0,07 & $-0,16$ & 0,10 & 0,01 & 0,12 \\
\hline Self-Development Motivation & 0,71 & 0,01 & 0,36 & 0,16 & $-0,02$ & 0,20 \\
\hline Self-Esteem Motivation & $-0,05$ & $-0,06$ & 0,84 & $-0,02$ & $-0,03$ & 0,08 \\
\hline Introjected Motivation & $-0,11$ & $-0,02$ & 0,82 & 0,07 & $-0,08$ & 0,09 \\
\hline External Motivation & $-0,20$ & 0,02 & 0,84 & $-0,02$ & 0,01 & $-0,07$ \\
\hline Motivation & 0,82 & 0,06 & $-0,27$ & $-0,07$ & 0,05 & 0,12 \\
\hline Self-control & 0,13 & $-0,01$ & $-0,47$ & 0,44 & $-0,03$ & 0,01 \\
\hline Serie A test Ravena & 0,03 & 0,37 & 0,21 & 0,47 & 0,07 & $-0,18$ \\
\hline Serie B test Ravena & $-0,15$ & 0,57 & 0,13 & 0,31 & 0,03 & 0,02 \\
\hline Serie C test Ravena & 0,20 & 0,70 & $-0,11$ & $-0,32$ & $-0,02$ & $-0,13$ \\
\hline Serie D test Ravena & 0,06 & 0,76 & 0,06 & 0,01 & 0,08 & $-0,01$ \\
\hline Serie E test Ravena & 0,08 & 0,78 & $-0,16$ & $-0,06$ & $-0,13$ & 0,03 \\
\hline Raven's overall test score & 0,10 & 0,99 & $-0,03$ & 0,02 & $-0,02$ & $-0,06$ \\
\hline
\end{tabular}

Conclusion. Our research has led us to the following conclusions. First, a viable strategy is to focus on the final score students receive for an online course. On average, it turned out to be higher than the score for an offline course. This may be explained by the ease of success achievement rather than by the benefits of the online format. Secondly, the relevant psychological characteristics identified in research literature may need to be revised and supplemented. As social reality is rapidly transforming and there is a growing need to study the psychological characteristics of people by applying objective (hardware, psycho-physiological) methods, this 
leads us to question the relevance of classical psycho-diagnostic tools. Third, the discrepancy between the results of this study and international data may be caused by the peculiarities of using online courses in Russia. When imposed in a top-down manner, online learning loses its advantages while its disadvantages become much more pronounced. Therefore, an important task of education in Russia is to preserve online learning in its most productive form, without turning it into 'window-dressing. The latter tendency causes concerns on the part of students and faculty. The key conclusion of this study is that a successful student is successful in any learning format. Probably, the search for ways to improve the efficiency of online learning should be focused not on the psychological characteristics of students who are successful in the online format, but on improving the pedagogical design of an online course.

\footnotetext{
1. Chang Y.-C., Kao W.-Y., Chu C.-P., Chiu C.-H A learning style classification mechanism for e-learning // Computers and Education. 2009. № 53(2). P. 273-285.

2. Broadbent J. Academic success is about self-efficacy rather than frequency of use of the learning management system // Australasian Journal of Educational Technology. 2016. Vol.32, № 4. P. 38-49.
} 